\section{Las rutas del Sollipulli hacia el Puel Mapu}

Sollipulli routes towards Puel Mapu

Marcelo Godoy

\section{Resumen}

El presente artículo da cuenta de los resultados etnográficos del proyecto FONDECYT 1060216/1130730, en particular, nos referimos a una investigación centrada en la caracterización de la movilidad por los caminos transcordilleranos de la zona de Sollipulli Villarrica. Allí pudimos recorrer, registrar y caracterizar algunas de sus rutas, así como también relevar la importante tradición oral mapuche que existe en torno a las prácticas y saberes asociados al viaje.

Palabras clave: rutas, paisaje, prácticas, saberes, Araucanía Andina

Dirección Museológica, Universidad Austral de Chile. Casilla 586. Correo electrónico: marcelogodoy@uach.cl

\section{Abstract}

The following article relieves the ethnographic results of the project FONDECYT $1060216 / 1130730$. Specifically, we refer to research focused in the characterization of the mobility on the roads covered by the area betweeen Sollipulli - Villarrica. We were able to travel, register and characterize some routes, as well as relieve important oral issues related with practices and knowledge associated to the trip.

Key words: pathways, landscape, practices, knowledge, Araucanía Andina.

\section{Introducción}

"En la medida que se dejan de transitar dejan de ser caminos", ésa es la sentencia con la que el lonco del sector de Chocol, en el Valle de Reigolil, resume su experiencia en torno a la movilidad por las tierras altas de la Araucanía, en el derrotero que ha sido descrito como una de las áreas de acceso al Puel Mapu, camino de maloqueros y conchavadores de distintos grupos étnicos, camino de funcionarios coloniales, militares y comerciantes, quienes desplazándose por angostas huellas o caminos de carretas, fueron configurando un territorio que, lejos de ser un obstáculo, es y ha sido un espacio altamente apetecido por las bondades de sus recursos alimenticios y materias primas para aplicaciones tecnológicas, además del alto valor simbólico que representa para el mundo mapuche los mawida o cerros. La cordillera no implica una barrera infranqueable, sino que representa el acceso a nuevos nichos ecológicos, a nuevos paisajes, y representa un área de alto contacto intercultural y paso obligado desde la selva valdiviana a la estepa patagónica.

ARTÍ́CULO 
Lo que a continuación presentamos es un ejercicio preliminar que pretende comprender la lógica de la movilidad por esos caminos cordilleranos, mediante la experiencia vivida del viaje pedestre, la caracterización de dichas rutas a través de su registro en notas de campo, SIG, y en el repertorio de testimonios recogidos con diferentes comuneros que se han desplazado por dichos derroteros, y que amablemente nos han compartido, para conocer las prácticas de movilidad por la Araucanía Andina en la zona que comprende los Nevados del Sollipulli hasta el Volcán Villarrica.

\section{1. Área de investigación}

El trabajo se concentró principalmente en el área del Villarrica - Sollipulli, en las comunas de
Panguipulli (Los Ríos), Villarrica, Pucón, Cunco y Curarrehue (Araucanía), donde se agrupan los lagos Villarrica, Caburgua, Colico y Calafquén, y los volcanes Villarrica (2.840 m.s.n.m.) y Nevados del Sollipulli (2.282 m.s.n.m.). A nivel específico, el registro cartográfico detallado se concentró en el eje Caburgua - Reigolil. Esta área se caracteriza por la presencia de los cursos de agua Maichín (baja en dirección norte sur hacia Curarrehue tributando con el Trancura), Sollipulli y Río Blanco (ambos desembocan en el Caburgua). El área tratada incluye también el valle alto y longitudinal de Reigolil y Curarrehue, y los boquetes cordilleranos allí asentados, particularmente el paso Reigolil - Pilhue. En el área descrita predomina el bosque caducifolio mixto de la Cordillera de los Andes, dado por la asociación del bosque de raulí (nothofagus alpina) y coihue (nothofagus dombeyi) y del

Imagen 1. Mapa del área general de la investigación con cotas y tipos forestales

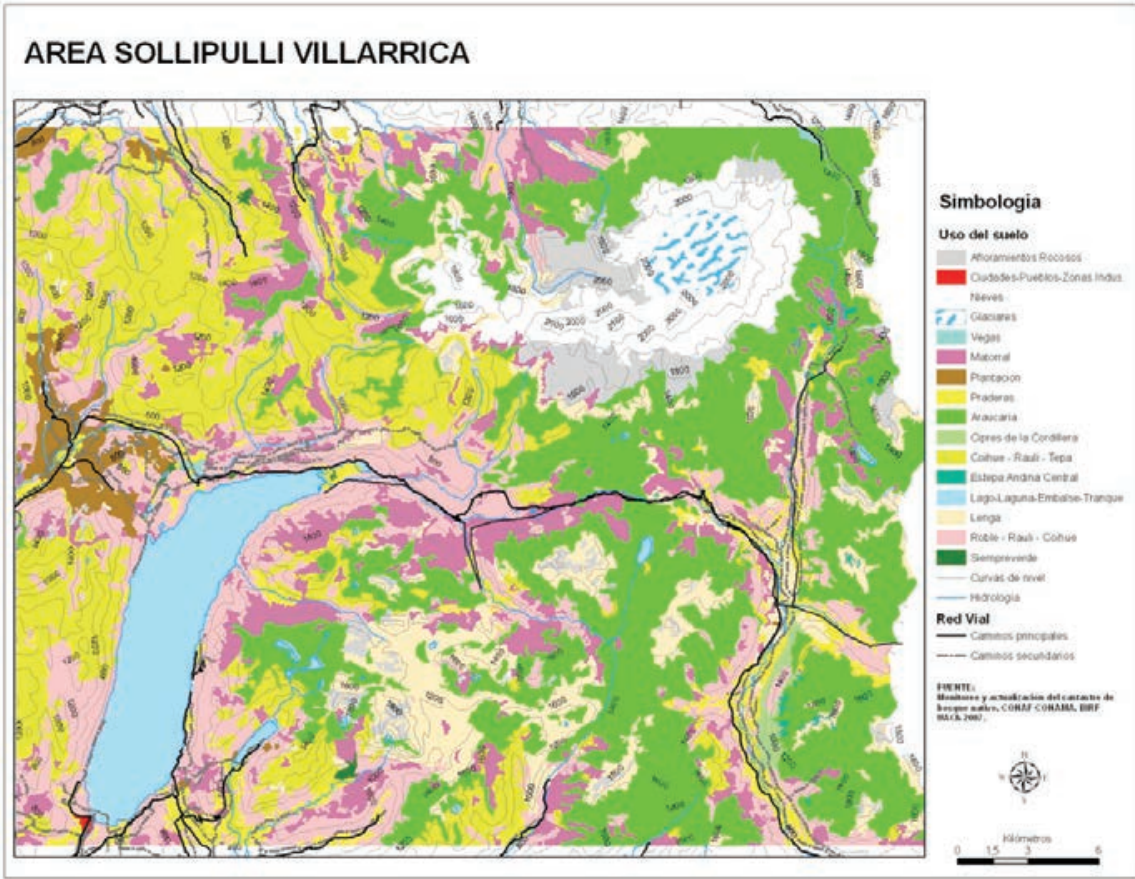


bosque laurifolio de los lagos, donde prevalece el ulmo (eucryphia cordifolia), la tepa (laurelia philippiana) y el tineo (weinmannia trichosperma), y por sobre la cota de 800 m.s.n.m. preponderan los bosques de araucaria (araucaria araucana) y el ciprés de la cordillera (austrocedrus chilensis).

\subsection{Metodología}

Para caracterizar y comprender la movilidad de esta zona se trabajó con herramientas cualitativas propias del método etnográfico, además del uso de tecnología SIG para el modelado de las rutas. La recolección de datos se organizó bajo dos modalidades: a) rondas y prospecciones etnográficas para el desarrollo de las entrevistas a colaboradores locales, y b) recorrido por senderos para su descripción en notas de campo, registro fotográfico y GPS.

En lo que se refiere al trabajo etnográfico, se asumió una mirada que permitiera relevar información sobre la movilidad en torno a las experiencias cotidianas de los habitantes mapuche del área y que, a su vez, nos permitiera describir la experiencia del investigador al experimentar las condiciones de desplazamiento por la accidentada geografía lacustre cordillerana mediante su tránsito a pie. Los testimonios fueron recolectados mediante el uso de entrevistas semiestructuradas, mientras que para el registro y documentación de las rutas se utilizaron notas de campo y pautas de observación en el recorrido de los tramos.

En lo que se refiere al trabajo con los colaboradores locales, las entrevistas fueron realizadas en sus propias localidades, en las comunas de Panguipulli, Pucón y Curarrehue. Se trabajó en base a un acuerdo preliminar y de consentimiento informado. Por lo general, la modalidad comprendía el desarrollo de varias jornadas de entrevistas, algunas de ellas registradas en audio y otras en notas de campo. Las temáticas abordadas hacían alusión a las antiguas rutas, prácticas tecnológicas, y conocimientos asociados a la movilidad y la estacionalidad. Dada la edad de los entrevistados, no participaron de las caminatas, pero ellos dieron referencias de las huellas y rutas que después fueron transitadas y registradas.

Para el trabajo de reconocimiento y mapeo de las rutas de tránsito terrestres y borde lacustre identificadas a partir de la tradición oral, se utilizaron los GPS Trimble GeoXM y Trimble Recon Handheld + Pathfinder XC Receiver, además se trabajó con GPS Garmin Etrex HCX. Mediante el programa GPS Pathfinder Office versión 4.0 se implementó un diccionario de datos, modalidad que posibilitó el diseño y captura de una base de datos geo-referenciada en terreno. Los datos tabulados permitieron el análisis y modelado gráfico de la información.

\section{Discusión teórica}

Alvarado y Mera (2004) señalan que toda ocupación de territorio implica una construcción simbólica del espacio y del paisaje, entendiendo que el espacio "es también una construcción social imaginaria, en movimiento continuo y enraizada con la cultura" (Criado 1991: 8). El paisaje posee una connotación existencial donde se realizan "acciones e influencias recíprocas" entre los seres humanos, la topografía, la vegetación y el clima. En palabras de Pimentel, el espacio posee una dimensión física (ecológica y geomorfológica) y social (económica y 
Imagen 2. Mapa de las rutas del Sollipulli hacia el Puel Mapu

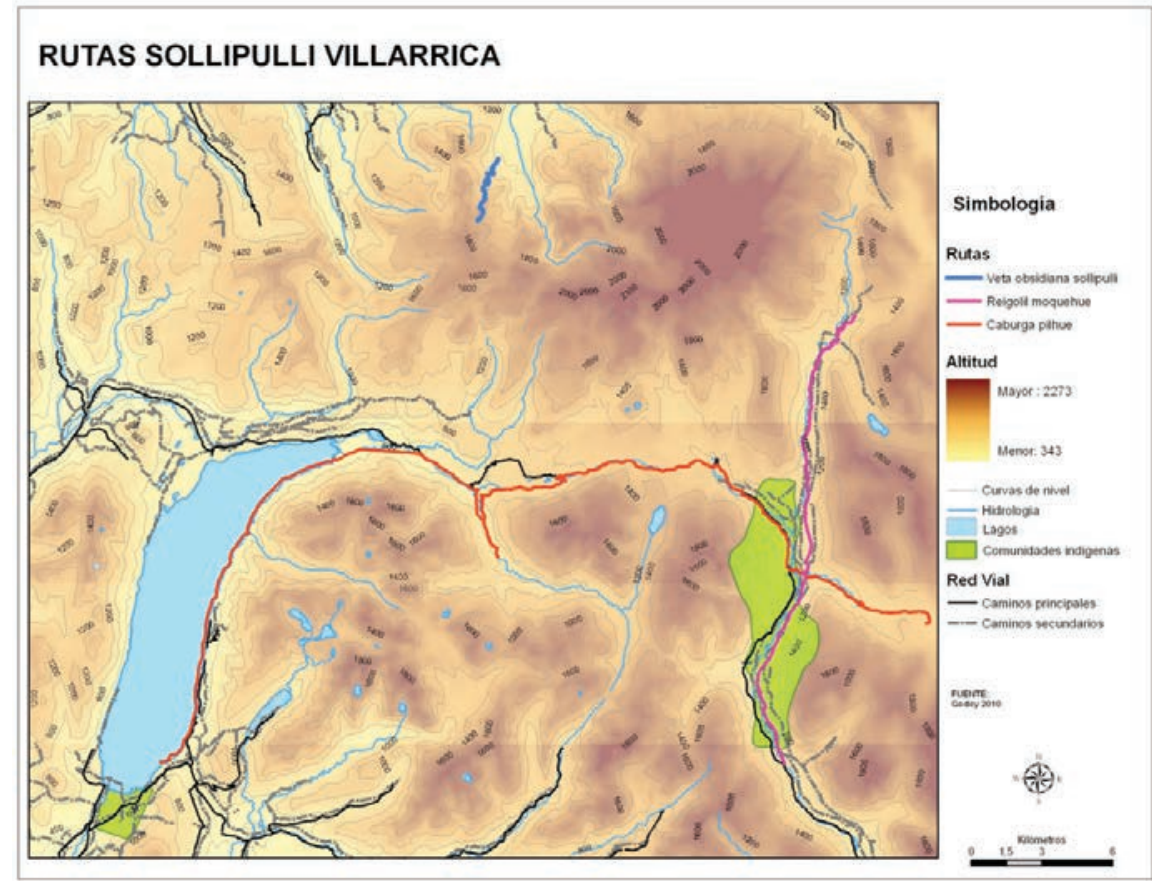

simbólica), puesto "que se construye a partir de la relación recursiva entre el ser humano y el medio, o en otras palabras, de tipo recíproco entre el comportamiento cultural y el medio circunscrito (Hodder y Orton 1990 [1976])" (2004: 45). Al respecto, Castro señala -a partir de su experiencia en el norte de Chile- que:

los seres humanos han otorgado a su paisaje una toponimia propia, llena de sentido, que constituye un conjunto de lugares relacionados e integrados por caminos, poblaciones móviles y narrativas, donde expresan sus percepciones y emociones. Es una topografía a la que se le ha conferido humanidad, transformándola en un código cultural relacionado con la vida (2004: 42).
La movilidad supone el viaje como un fenómeno social donde los individuos se desplazan en la búsqueda de respuestas a diferentes necesidades, en el que las rutas facilitan la conexión entre diferentes puntos geográficos $\mathrm{y} / \mathrm{o}$ asentamientos. Así, el territorio se construye en la medida que se camina, el viaje implica una experiencia para el viajante donde se significa o resignifica el entorno en el andar:

La acción de atravesar el espacio nace de la necesidad natural de moverse con el fin de encontrar alimentos e informaciones indispensables para la propia supervivencia. Sin embargo, una vez satisfechas las exigencias primarias, el hecho de andar se convirtió en una acción simbólica que permitió que el hombre habitara el mundo. 
Al modificar los significados del espacio atravesado, el recorrido se convirtió en la primera acción estética que penetró en los territorios del caos, construyendo un nuevo orden sobre cuyas bases se desarrolló la arquitectura de los objetos colocados en él (Careri 2002: 20).

De este modo, diferentes marcas y gestos se expresan en el paisaje, hitos culturales como sitios de arte rupestre, paradores, miradores, etc., dan cuenta de este hecho simbólico, así como también las connotaciones que se le entregan a determinados componentes del paisaje, tales como volcanes, cerros o cuerpos de agua.

Desde una mirada mapuche, las concepciones sobre espacio y territorio poseen particularidades que han sido analizadas y descritas por Ancán (2002), quien resalta que la concepción predominante del espacio mapuche se da en un eje oeste-este, a diferencia del eje nortesur que caracteriza occidente. Para Alvarado, "el mapu es el lugar de residencia y al cual [se] está ligado por lazos parentales y de linaje vinculados a los antepasados" (2004: 567).

En este contexto, resulta contundente la clasificación de los lugares que conforman el mapu realizada por Ancán (2002). Este autor distingue tres niveles, que abarcan desde el espacio doméstico a las grandes extensiones de territorio. Señala que:

el espacio doméstico [estaba] constituido por las agrupaciones de rukas de un lofche o "puebla", la unidad familiar básica mapuche, caseríos separados a una distancia no menor de 500 metros. Su entorno circundante, el paisaje humaniza- do, estaba compuesto de una quinta de árboles frutales domesticados, vertientes o surtidores de agua para beber, cursos de agua para limpieza, corrales para el ganado, potreros para sembradíos vinculados exclusivamente a las necesidades de consumo doméstico. Los terrenos usados para mantener la variable masa ganadera de los dueños de casa, no necesariamente estaban aledaños a la "puebla", salvo respecto al ganado destinado al consumo (2002: 133).

El segundo nivel hace referencia a los "espacios de uso cultural", distinguiendo zonas de uso público "asociadas a elementos naturales como árboles, aguas y tierra, en sus distintos y mutables estados" (2002: 133) de uso colectivo rotatorio (zonas de pastoreo, cultivo), zonas de uso cultural no productivo (zonas de agua y alturas), y zonas de uso público y carácter colectivo abierto (cementerios, canchas de nguillatun y paliwe). El tercer nivel corresponde "a aquellas tierras con todos sus accidentes aledaños, (...) siendo parte de la jurisdicción de algún lonko o ñidol lonko" (2002: 133).

Además, la concepción del espacio considera otros niveles del mundo que superan lo terrenal. Al respecto, Dillehay señala que en la cosmovisión mapuche "cada punto cardinal representa un grado menor de lo bueno, partiendo del este como punto de referencia inicial" (Cit. en Foerster y Gundermann 1996: 191). En este sentido, el rewe es un punto de encuentro entre el mapu humano y el mapu divino, hito colocado en un lugar específico para funcionar como un ordenador del paisaje, en que la disposición del Nguillatwe mirando al este, reproduce el orden cosmogónico horizontal cuatripartito, presente en el mundo viviente y el kultrung (Grebe, 
Pacheco y Segura 1972). Vale decir que este hito cultural constituye un elemento ordenador del paisaje, ya que de su condición simbólica se refleja también una dimensión ecológica, geomorfológica y social.

Por lo tanto, el viaje hacia el Puel Mapu, hacia las tierras del este más allá de las montañas, a través de los boquetes cordilleranos, significó para los antiguos mapuche una experiencia iniciática. En este sentido, el prestigio no sólo era fruto de los logros económicos, sino también de un desarrollo espiritual y personal, al que se ha sometido el viajante al superar las dificultades que entrañaba el viaje a esas tierras desconocidas del Chawneguechen.

Para tratar la noción de ruta, tomaremos las definiciones desarrolladas por Berenguer et al. (2005) en los trabajos que realizan en torno al Qapaqñam (norte de Chile), obviamente guardando las diferencias que supone el tratamiento de la movilidad en las rutas de la Araucanía, donde también se observa una burocracia que implementa un sistema de conexiones viales, lacustres y fluviales, en torno a los lugares de administración colonial, a partir de la fundación de Villarrica y Valdivia en el año 1552. Berenguer et al. (2005) desarrollan su propuesta teórica a partir de la presencia de rutas que conectaban la administración inca. Al respecto, proponen el uso del concepto de vía "para referirse genéricamente a cualquier curso de tránsito humano físicamente visible en el terreno (Hyslop 1984: 13), con independencia de su ancho, funcionalidad específica y características constructivas" (2005: 14). Además, proponen tres tipos de vías: caminos, senderos y sendas.

- El camino se trata de una vía formal que presenta evidencia de planificación y su construcción obedece a criterios de una administración del territorio. Tienden a ser vías preferentemente rectas y superan obstáculos geomorfológicos que optimizan el transporte entre los puntos que conecta.

- El sendero se trata de un "trazado informal, redundante y más geomórfico que un camino y que impresionará más como producto del simple y reiterado trajín de personas y animales, que de la planificación o la inversión de trabajo" (2005: 14).

- La senda se define, finalmente, como "una huella de trazado informal redundante y geomórfico de aproximadamente 30 a 50 centímetros de ancho que resulta del recurrente paso de transeúntes" (2005: 14).

Las vías reflejan las particularidades culturales de los grupos que las utilizan. Para Pimentel, los caminos son una expresión de las redes sociales que configuran "una relación espacial física y social con el entorno" (2004: 7). Por lo tanto, los caminos son variados en la medida que cada grupo étnico ha desarrollado sus propios recorridos, marcando de manera particular el territorio, en virtud del itinerario cultural con que ha rotulado ese paisaje en su andar.

La documentación histórica (León 1991) da cuenta de una variabilidad étnica del área del Sollipulli - Villarrica, por lo tanto, las antiguas rutas constituyeron un mosaico de prácticas que trataremos de entender mediante su recorrido y testimonios. En este sentido, las rutas representan un sistema de relaciones y significados que se construyen desde el cotidiano y desde la cosmovisión, por ello es que tam- 
bién resulta interesante incluir las categorías de movilidad que hacen referencia a modalidades que presentan evidencia de cultura material, como las que se expresan en la tradición oral de la cosmovisión mapuche y que trataremos a lo largo de este trabajo.

\section{Las rutas del Puel Mapu}

\subsection{Antecedentes}

Para el ámbito lacustre cordillerano, en trabajos arqueológicos recientes, la movilidad se refleja en diversas expresiones de cultura material. Bellelli, Scheinshon y Mercedes (2008) indican que los pasos o rutas transcordilleranas se caracterizan por la presencia de pasos cordilleranos de baja altura, lo que ha permitido entender la lógica de la movilidad de Argentina a Chile. A partir de sus estudios en la zona del Manso - Paso El León, concluyen que el rasgo diagnóstico más evidente de movilidad está representado por las regularidades estilísticas encontradas en sitios arqueológicos asentados en el sistema fluvial que conecta Argentina y Chile, conformando indicadores de circuito. Al respecto, señalan que "los sitios con arte rupestre podrían funcionar como hitos idiosincráticos para demarcar una ruta previamente reconocida (wayfinding) (Golledge 2003), que sólo son significativos para un individuo o un grupo sociocultural" (Bellelli, Scheinshon y Mercedes 2008: 51). Para Albornoz y Hajduk (2003), la Cordillera de los Andes no constituyó una barrera para los humanos que habitan y habitaron ambas vertientes cordilleranas, esta afirmación la realizan a partir de la investigación llevada a cabo en Puerto Tranquilo 1 (1.310 D.C.), Isla Victoria, Lago Nahuelhuapi, Bariloche, Argentina (Hajduk 1990 Cit. en Al- bornoz y Hajduk 2003), donde se "refleja una convergencia de rasgos materiales de diverso origen, confirmando lo que expresan las crónicas escritas (...) de ser esta región un área de intenso contacto e intercambio cultural" (2003: 2).

En el trabajo de Stern et al. (2009) se da cuenta de una amplia movilidad desde y hacia ambos lados de la cordillera, a partir del análisis de material lítico, estudiando 35 muestras de obsidiana, de las cuales 20 son adscritas a la fuente o veta ubicada en los Nevados del Sollipulli, las que se distribuirían ampliamente desde la estepa argentina hasta la costa y sección media de Chile septentrional. Las muestras de obsidiana gris se adscribirían al Volcán Chaitén y las muestras transparentes y rojas $(\mathrm{N}=9)$ provendrían de la zona cordillerana de Neuquén. Los autores señalan que el tránsito de la obsidiana hacia ambos lados de la cordillera se dio por el paso de Icalma (1.300 m.s.n.m.), sin embargo, esta afirmación debiera cotejarse en virtud de la presencia de numerosos pasos en la propia zona del Sollipulli, como ocurre con el paso de Reigolil - Pilhue, paso ostensiblemente menos alto y menos complejo en su movilidad en cualquier estación del año, y mucho más cercano para acceder a la veta presente en los Nevados del Sollipulli. En la Tabla 1 podemos apreciar las muestras de material lítico, que dan cuenta del uso de la materia prima adscrita a las rutas en el sector Sollipulli - Villarrica.

Otro aspecto que da cuenta del tránsito frecuente en la zona cordillerana lo podemos constatar a través de las investigaciones arqueológicas realizadas por Mera et al. (2004) en la zona del Villarrica para los tiempos de la Colonia Temprana. En este trabajo se informa y caracteriza una red de 11 fortines, cuyos fe- 
Tabla 1. Distribución de sitios con presencia de obsidiana analizados por Stern et al. (2009)

\begin{tabular}{|c|c|c|c|c|}
\hline Sitio & Latitud Sur & Longitud Este & Elevación & No. de muestras \\
\hline Alero Cabeza de Indio 1 & $-38^{\circ} 45^{\prime} 60^{\prime \prime}$ & $-71^{\circ} 33^{\prime} 57^{\prime \prime}$ & $842 \mathrm{msnm}$ & 15 \\
\hline Fundo Tres Arroyos 1 & $-38^{\circ} 58^{\prime} 47^{\prime \prime}$ & $-72^{\circ} 01^{\prime} 45^{\prime \prime}$ & $410 \mathrm{msnm}$ & 3 \\
\hline Flor del Lago 1 & $-39^{\circ} 12^{\prime} 20^{\prime \prime}$ & $-72^{\circ} 07^{\prime} 34^{\prime \prime}$ & $197 \mathrm{msnm}$ & 1 \\
\hline Los Riscos 1 & $38^{\circ} 53^{\prime} 05^{\prime \prime}$ & $-71^{\circ} 50^{\prime} 34^{\prime \prime}$ & $463 \mathrm{msnm}$ & 4 \\
\hline Quillen 1 & $-38^{\circ} 25^{\prime}$ & $-72^{\circ} 35^{\prime}$ & & 2 \\
\hline Granaderos-2 & $-37^{\circ} 59^{\prime}$ & $-72^{\circ} 15^{\prime}$ & & 1 \\
\hline Chan Chan-18 & $-39^{\circ} 34^{\prime}$ & $-73^{\circ} 16^{\prime} 54^{\prime \prime}$ & $12-19 \mathrm{msnm}$ & 6 \\
\hline Puente Quilo & $-41^{\circ} 51^{\prime} 36^{\prime \prime}$ & $-73^{\circ} 59^{\prime}$ & $2-4 \mathrm{msnm}$ & 3 \\
\hline
\end{tabular}

chados proponen una ocupación que abarca un periodo entre los años 1.340 al 1.605 D.C. La distribución de los sitios se concentra en la zona oriental del Villarrica (8), mientras que los restantes se concentran en la ribera norte del Lago Calafquén (2) y ribera sur del Toltén (1). Mera et al. (2004) sugieren también un uso indígena de este tipo de sitios, y lo definen en torno a una estrategia de control territorial, ya que las fuentes históricas, los detalles arquitectónicos de los mismos y el fechado pareciera así indicarlo. En consecuencia, se evidencia un control territorial en la zona de los pasos transandinos, probablemente por los conflictos que se dieron entre los diferentes grupos indígenas apostados a ambos lados de la cordillera.

Según León (1991), era habitual el tránsito por la Cordillera de los Andes hacia la pampa argentina de parte de numerosos grupos étnicos abocados a la guerra del malón, principalmente huilliches, pehuenches, aucas, tehuelches y otros grupos menores, como tehuelches del Río Negro y los chiquillanes de los valles intracordilleranos durante el siglo XVIII. León sostiene que la movilidad se manifestaba a través del uso de rutas que eran conocidas como "el "Camino de los chilenos" o "Rastrilladas", sien- do ésta una extensa red de surcos o zanjas que cruzaban las pampas, reflejando físicamente los movimientos periódicos de los maloqueros entre Chile y Argentina" (1991: 70). De hecho, la zona cordillerana Villarrica - Sollipulli era parte de la red de caminos que comunicaban Valdivia con Buenos Aires. León describe que "el padre Cardiel había discurrido que los usuarios de aquel camino "eran Indios Araucanos, o algunos vecinos a éstos, que habitaban en la costa de Chile, y á tiempos hacían sus viajes para llevar de las lagunas de San Julián algunas cargas de sal"1 (1991: 71). Treinta años más tarde, José de Orejuela propuso a la corona la ocupación de estas rutas para inaugurar un sistema de comunicaciones entre Buenos Aires y Valdivia, utilizando el paso situado al interior de Villarrica que estaba abierto todo el año y que era "camino de carretas" 2 . Otro misionero, que actuó como capellán de la expedición que se

Joseph Quiroga: "Relación Diaria, que hace al rey Nuestro Señor el p. Joseph Quiroga de la Compañía de Jesús, de el viage que hizo de orden de S.M. a la costa de Patagones en el navío San Antonio, mandado por Don Joaquín de Olivares, que salió del Río de la Plata siendo capitán y Gobernador General de esta Provincia Don José de Andonaegui el año de 1745”. B. L., Add. Mss. 17.607, f. 132.

$2 \quad$ Joseph de Orejuela: "Memorial presentado al Rey sobre la Reconquista y Descubrimiento de la ciudad de Osorno, 28 de junio de 1775". B. L., Add. Mss. 15.795, f. 84. 
envió en busca de la fabulosa Ciudad de los Césares, manifestaba en 1778 que los caciques de Osorno rehusaron entregar noticias sobre la ubicación del camino de Villarrica, porque temían que los españoles lo usaran en el futuro para "maloquearlos"3.

Por su parte, Ancán (2002), luego de realizar el rescate de testimonios sobre el viaje a las pampas, señala que el paso de Villarrica (actual Mamüll Malal) es reconocido por sus entrevistados como el más antiguo y reputado dada su transitabilidad casi ininterrumpida durante todo el año. A ellos se sumaban los pasos de los lagos Lacar y Pirihueico (actual paso Huahum), los de Ranco y Riñihue, junto a una gran cantidad de pasos menores que mantenían un permanente flujo transcordillerano: "Testimonios como los de Pascual Koña y otros muchos, certifican que a lo largo de todo el recorrido de ese río [Toltén], por su orilla sur, iba adosada una huella que se prolongaba desde la costa del lago Budi hasta los pasos cordilleranos de Villarrica, Paimún y Carrerriñe" (2002: 116).

\subsection{Resultados de la investigación}

A continuación se presentan los resultados de la investigación, los cuales se dividen en dos bloques. En el primero de ellos se aborda el corpus de datos etnográficos relevados en el área de trabajo, y que da cuenta del profundo conocimiento del territorio y de las soluciones tecnológicas aplicadas en el desplazamiento pedestre y por cuerpos de agua fluvial o lacustre. En el segundo bloque se presentan los resultados de las rutas que fueron relevadas por

Benito Delgado: "Diario del capellán de la expedición que se hizo para el descubrimiento de la Ciudad de los Césares, 12 de marzo de 1778". Gay, vol. 1, p. 481. la tradición oral, y que fueron cartografiadas y caracterizadas mediante su viaje y registro SIG. Al final, se plantea una discusión sobre la naturaleza de las vías estudiadas.

\subsubsection{Discusión de rutas a partir de los da- tos etnográficos}

La tradición oral presente en el área Sollipulli - Villarrica da cuenta de prácticas sociales y tecnológicas que permitieron recorrer, categorizar y usar el territorio mapuche; los itinerarios de movilidad se expresan a través de un amplio sistema de vías, a través de las cuales se puede acceder a distintos puntos del territorio, siguiendo variadas opciones por tierra firme y cuerpos de agua. En la Araucanía Andina, para el mundo mapuche, el futarepu o sendero principal, y el chekerrepu o senda vecinal, están orientados a resolver las necesidades de transporte y comunicación cotidianas, para la recolección estacional, visitas a familiares, para realizar trafkin o intercambio con poblaciones de otros sectores.

Las hazañas de los antiguos habitantes han quedado estampadas en dichos paisajes y rutas, ejemplo de ello es lo que recuerda Don Fermín $^{4}$, del sector Los Traros-Flor del Valle, a los pies de los Nevados del Sollipulli, quien señala que "de esa descendencia somos nosotros, de esos viejos bravos de antes, ésos que iban a la Patagonia a guerrear con los españoles hacia sus trincheras". Este testimonio da cuenta de prácticas de movilidad hacia ambas vertientes de la cordillera, de hecho, en la zona se recuerda que los caminos más usados para viajar hacia Argentina eran el paso a Coloco, Pilhue y

\footnotetext{
Fermín Quintunahuel (78), sector Flor del Valle, Reigolil, comuna de Curarrehue.
} 
Moquehue, y desde el sector cordillerano a los valles de interior chileno eran el camino vía Curarrehue-Itrapulli-Pucón y otra vía Río BlancoCaburgua-Pucón o Río Blanco-Caburgua-Cunco. Para el tránsito hacia el lado argentino, los testimonios hacen referencia al uso permanente de los pasos de Coloco, Pilhue y Moquehue, sin embargo, el más preciado es el de Pilhue, que conectaba ambas vertientes a través de un portezuelo bajo, y desde allí se accedía a las localidades de Moquehue y Aluminé en Argentina.

Testimonios recabados en el sector de Quelhue dan cuenta del traslado y relocalización del ganado en zonas de veranadas para el talaje. Sobre las actividades de comercio, se describen viajes de caballo y carretas para comerciar productos provenientes de ambos lados, desde Chile se comerciaba tejidos, harina y vino, mientras que desde Argentina traían ganado y yerba mate. Al respecto, don Alberto Colipe ${ }^{5}$ recuerda que las cargas "salían de Pucón, pasaban a Curarrehue y de ahí pasaban por Mamuil Malal (...). Ahí en Quillelhue pasaban en una balsa empujada por una lanchita también". Según don José Paredes ${ }^{6}$, por el lado este del Lago Caburgua se realizaba todo el movimiento de ganado, recuerda que "a este lado estaba todo el movimiento, por el otro lado no había mucho movimiento, era todo para este lado en el fondo, para el lado de Argentina y se partía desde abajo desde (...) Renahue (...) y habían dos opciones para subir animales: por Río Blanco directamente y la otra por Renahue". En aquellos viajes, el itinerario comenzaba al despuntar el alba, se prefería viajar de mañana, a pie o caballo, y la proporción de horas destinadas para cubrir los tramos era bastante parecida si

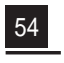

se utilizaba una u otra opción de ruta, con la diferencia de que sobre el caballo el viaje era más descansado y posibilitaba el traslado de carga.

En los relatos también se da cuenta de los viajes hacia el interior, se recuerdan rutas que prácticamente conectaban el sector Sollipulli - Villarrica con Valdivia. Un ejemplo lo constituye un relato de actividades de comercio entre Reigolil y San José de la Mariquina: "por Caburgua porque había camino, si era malo el camino, para andar de caballo nada más, por orilla de playa hasta para el lado izquierdo de aquí para allá, se iba para abajo hasta despuntar el Caburgua, hasta llegar a Pucón y así pegando para allá" hasta San José de la Mariquina. Otros relatos, recogidos en la localidad de Quelhue, en las cercanías de Pucón, dan cuenta de los viajes que realizaba la gente del interior hacia la zona de pinalerías para la extracción de piñón en los meses de su recolección (abril-mayo), principalmente de gente avecindada en las cercanías de Loncoche.

Otro componente significativo en las prácticas de movilidad son las zonas de descanso y/o refugio. Hasta el día de hoy se utilizan aleros o reparos rocosos para el abrigo, algunos de ellos constituyen lugares de poder para el mundo indígena y, por ende, presentan un uso de carácter ritual, como ocurre con las casas de piedra del sector de Chocol. Los testimonios también señalan que los mismos aleros o reparos rocosos fueron utilizados para que las familias se refugiaran en el contexto de la Guerra del Desierto y en la "Pacificación de la Araucanía", por lo tanto, para muchas familias, esos lugares representan parte de la historia familiar. Otros testimonios refieren el uso de parte de trabajadores forestales, como ocurre con el Alero Cabeza de Indio en la comuna de Meli- 
peuco y el Sitio de Arte Rupestre La Zueca, en el sector de Renahue, en la comuna de Pucón (cuyo nombre se asocia a un ocupante que hacía uso de ese tipo de calzado a mitad del siglo XX en la explotación de madera).

Sobre el uso de los refugios, la tradición oral también consigna el uso de tolderías hechas de colihue en los periodos de recolección de piñón. Para el caso de tener que pernoctar en un lugar poco apropiado, y sin posibilidad de armar una toldería, se recuerda el uso de la quila como aislante, que se extrae y se coloca a modo de colchón para evitar contacto directo con el suelo. Don Fernando Huaquifil, Ionco de la comunidad de Quelhue, señala que en la época de recolección de piñones, se accedía a las pinalerías de Huerquehue, por el sector de la Laguna Tinquilco, viajando un día a caballo para llegar hasta las terrazas. La faena de recolección duraba en promedio 5 días para realizar acopio, esperando que el viento colaborara en el lanzamiento de piñones desde sus ramas. Cuando las condiciones del viento no eran las óptimas, se optaba por que uno de los integrantes del grupo trepara el árbol, y con una garrocha de colihue desprendiera los frutos dando golpes sobre la mata de piñones. Durante esos periodos de recolección habilitaban una rancha de dos aguas, de aproximadamente $4 \mathrm{~m} .2$ por $2 \mathrm{~m}$. de alto. Era fabricada en base a quila y colihue con hojas, tejido de manera entrecruzada para evitar que se filtre viento y agua, el fogón siempre estaba dispuesto en la entrada de la tienda. Una vez realizada la recolección se dejaba la tienda, siendo ocupada posteriormente por otros recolectores.

Para el desplazamiento con presencia de nieve se desarrolló la chihua, una especie de sandalia ancha hecha de colihue, y que se ajustaba a los pies para poder caminar sobre la nieve, y así, resolver el traslado hacia diversos puntos, a pesar de los obstáculos que plantea el invierno en los senderos montañosos. Otra práctica recordada es el uso de troncos ahuecados como espacios de refugio, y al igual que en las casas de piedra, para algunos troncos se recuerda un uso ritual. Un ejemplo del uso de los trincos ahuecados como espacio de significación se recuerda en la zona de Tinquilco-Caburgua, la señora Hil$\mathrm{de}^{7}$-descendiente de colonos asentados en la zona- recuerda que "[a] ese tronco mi papá le puso la iglesia porque los mapuches cuando se robaban una niña, cuando estaban pololeando se robaban una niña, la tenían escondida, hasta que el chucao cantaba tres veces, una semana era el plazo, podía estar perdida la niña, después ya el papá mandaba gente con lanza y con armas a buscar a la hija, y cuando cantaba tres veces era ley que se casaban".

Desde el punto de vista tecnológico y asociado a necesidades de transporte y comunicación, en las zonas con presencia de cuerpos de agua se recuerda el uso de canoas y luego botes en los lagos Caburgua, Villarrica y Calafquén, y en la zona de Quelhue, en la comuna de Pucón, se realizaba balseo haciendo uso de canoas monóxilas para vadear el Río Trancura. Don Fernando Huaquifil ${ }^{8}$ recuerda que "como habían palos gruesos acá, laureles, se les ocurrió hacer una canoa a los más antiguos, a los primeros nativos que vivieron aquí, así que abajo lo vaciaron adentro con hacha, y ahí fabricaron la canoa, y con esa pasaban el río, como el río era angosto, y después se hicieron una paleta, como remo y ahí atravesaron el río, pasaban el Río Trancura de Quelhue a Pucón".

\footnotetext{
Tante Hilde (70), Lago Tinquilco, comuna de Pucón. Fernando Huaiquifil Cucha (91), sector Quelhue, comuna
} de Pucón 


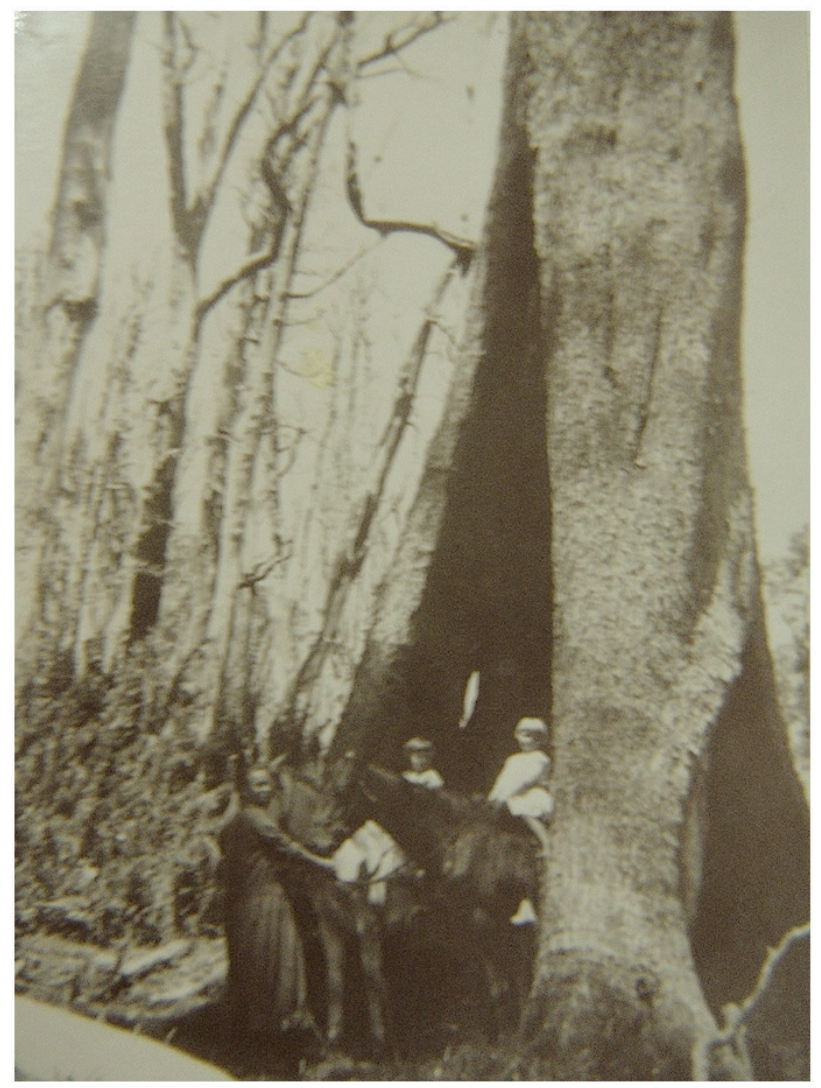

Estas canoas de tipo monóxila eran hechas en base a una pieza en madera de laurel (laurelia sempervirens) o lingue (persea lingue), y se utilizaban cuando las condiciones climáticas permitían su navegación para el traslado de personas o carga entre diversos puntos de las cuencas lacustres y fluviales. La navegación con canoas o wampos estaba articulada por una serie de puertos, y se recuerda que en las zonas de atraque de las embarcaciones solía existir un responsable de ella (Godoy y Lira 2007). Cuando se requería de la embarcación, por lo general, se utilizaba un sistema de señales de humo o de fütrunkütral desde puntos estratégicos convenidos para el avistamiento y llamado de balseo, así como también el uso del kurküll, corneta hecha en base a los cachos de vacuno. Lo interesante del uso de estos instrumentos y códigos de llamado da cuenta del uso sistemático y permanente de un sistema de comunicaciones que facilitaba la generación de acciones a distancia.

Sobre el kurküll, entendido como instrumento sonoro de avisaje, los testimonios describen que "antes los antiguos lo hacían con sus poderes, (...) de ahí se comunicaban con Argentina que es nuestro país vecino (...). Entonces 
el lonco llamaba a su cona, que toque el kürküll para tener reuniones, entonces se escuchaba uno a una distancia y ahí tocaba el otro el kürkül y se iba, así que en un par de horas estaban todos reunidos en la casa del lonco, y ahí le decía el lonco esto viene, este malón viene, o esta guerra viene, preparémonos, y ahí empezaban a fondearse en el mawida (...) entonces otro contestaba, el otro aunque fuera cualquiera de la gente escuchando agarraba también su kürküll y se iba, podía llegar en un par de minutos, podía estar en Argentina o en Santiago o en todo Chile"'.

Este relato da cuenta de una modalidad de comunicación ya institucionalizada, que refiere a la constitución de un territorio configurado en base a alianzas de loncos, y que en caso de conflicto con terceros, disponía de procedimientos de movilidad y control del territorio, generando la ocupación de asentamientos en posiciones de altura (cerros o promontorios), para disponer de un control visual del territorio y los desplazamientos de los eventuales enemigos. De este modo, fortines indígenas descritos en posiciones de altura como el de Cahiuncul, en el sector de Llongahue, comuna de Panguipulli, avalan esta práctica de movilidad y control territorial.

Lo cierto es que de todas esas prácticas de movilidad, que se expresan en tanto respuestas tecnológicas y conocimientos de orden pragmático, se vinculan a formas de conocimiento mágico-religioso. Existe un ámbito de conocimiento escasamente registrado en la literatura etnográfica del pueblo mapuche, y es el que hace referencia a aquellos caminos sagrados, que obran sólo por el "poder lonco", quien co-

\footnotetext{
9 Pedro Punoy (83), sector Cayumapu Alto, comuna de Pan-
}

nociendo las fuerzas de la naturaleza era capaz de conformar kurcos y puentes wespe ${ }^{10}$. Los primeros eran túneles que subterráneamente permitían la conexión entre puntos apartados, especialmente para relacionar vertientes contrarias de los cerros o volcanes. El segundo tipo corresponde a puentes que conectan diversos puntos entre las riberas lacustres, y para su confección también operaba el poder del lonco, quien por su influjo, podía construir estructuras hechas en base a las tripas de animales de poder (según el mito mapuche se trata de animales que nacen en los hualves, en la zona cordillerana se habla del toro amarillo). Al respecto, don Pedro Punoy ${ }^{11}$ recuerda que los puentes wespe "se hace[n] con cables (...) pero de tripas de estos animales del agua, pasan ellos [los mapuche] y atrás (...) jasí fue como ganaron la guerra contra los españoles aquí en Chile". Sobre estos itinerarios sabemos muy poco, pero, sin duda, su recuerdo da cuenta de un profundo conocimiento del territorio y de los accidentes geográficos, que facilitaron el uso de rutas 0 vías que eran conocidas por unos pocos viajeros o guías del antiguo mundo mapuche.

\subsubsection{Registro y caracterización de rutas}

El trabajo realizado en la zona del Villarrica Sollipulli nos permitió caracterizar y describir un área en la que converge un conjunto de vías que definen rutas o itinerarios al Puel Mapu y a zonas de acceso a recursos (rutas de acceso a pinalerías, zonas de veranada y zonas de acceso a materia prima lítica). A continuación, la discusión se centrará en la caracterización de tres

\footnotetext{
Pedro Punoy (83), sector Cayumapu Alto, comuna de Panguipulli.

11 Pedro Punoy (83), sector Cayumapu Alto, comuna de Panguipulli.
} 
rutas presentes en el área Villarrica - Sollipulli, y cuyo derrotero fue construido con el aporte de datos etnográficos recogidos de las entrevistas a habitantes de la zona de Cayumapu, Quelhue, Caburgua, Río Blanco, Reigolil, Chocol y Flor del Valle.

Las rutas que hasta el momento han sido identificadas para la zona del Villarrica - SollipuIli nos permitieron reconocer al menos ocho pasos. De sur a norte encontramos: Carirriñe (1.223 m.), Mamuil Malal (1.253 m.), Tromen (1.316 m.), Malaco (1.525 m.), Coloco (1.417 $\mathrm{m}$.$) , Reigolil-Pilhue (1.120 m.), Nellocahue o$ Moquehue (1.444 m.) e Icalma (1.300 m.). De este total, abordamos los casos de Reigolil Pilhue y de Nellocahue, e incluimos un tercer caso asociado a la ruta de acceso a una fuente de obsidiana en los Nevados del Sollipulli. En el siguiente apartado se describen tres rutas consignadas en el área, dos que son descritas para tránsito hacia Argentina, y una de acceso a la veta de obsidiana en los Nevados del Sollipulli.

\subsubsection{Ruta Caburgua-Reigolil (Chile) - Pil- hue (Argentina)}

En los testimonios recogidos se habla frecuentemente del paso Pilhue como un antiguo camino hacia Argentina, también se le conoce como paso Reigolil, es uno de los boquetes cordilleranos usado de manera permanente dada su baja altura, baja dificultad en su desplazamiento (es un camino de escasa pendiente y de huella muy clara), y antiguamente de permanente uso para traslado de ganado, realizar compras de víveres y otros insumos en los poblados argentinos adyacentes. Junto con los datos consignados en la tradición oral, los testimonios de cultura material, principalmente a través de registros de Arte Rupestre ubicados en el Alero La Zueca, en la ribera este del Lago Caburgua (Renahue), indican pautas de movilidad transandina desde alrededor del 1.310 D.C., dado el estilo de grecas consignado por Belleli, Scheinshon y Mercedes (2008) para sitios ubicados en la zona del Manso Puelo, en la Región de Los Lagos.

Uno de los testimonios recogidos en la ribera norte del Caburgua recordaba el tránsito desde el Valle de Reigolil, hasta las cotas más bajas donde se encuentra el Lago Caburgua y, desde allí, del sector Río Blanco a Pucón. El itinerario contemplaba el uso de senderos por tierra y trayectos por el Lago Caburgua, ambos fatigosos y de cuidado. Para el tránsito por el cuerpo de agua, lo que se realizaba era avanzar "costeando" de puerto en puerto, principalmente por la dificultad que impone la fuerza del viento, corrientes y oleaje.

Lo indicado por nuestra entrevistada fue consignando con la caracterización de dos huellas, una por Renahue y otra por Caburgua, mientras que para la navegación se recorrió la red de 7 puertos o embarcaderos en el lado oriental del Lago Caburgua: 1) Las Pitras, 2) Piedra de Águila, 3) Renahue, 4) La Siete, 5) Playa Blanca, 6) El Llolli-Los Osorio, y otros en el sector norte: Borde de Piedra y Llanqui-Llanqui (Playa Negra). Todos estos puertos permitieron la conexión de Pucón y Cunco, hacia Río Blanco, Quililche y el Valle Alto del Reigolil. En el sector noreste del lago, se habilitó una bodega (Los Osorio) para que la gente de Río Blanco pudiera almacenar su carga hasta que lograraser trasladada a caballo hasta la localidad de Río Blanco (punto 10), inclusive hasta el sector de Quililche, ya en cotas superiores a los 700 m.s.n.m. (punto 12-13). Cuando las condicio- 
nes de navegación eran adversas se realizaba el recorrido entre Río Blanco y Caburgua, a través de un sistema de huellas que se desplaza bordeando los ríos Blanco y Sollipulli, o bien escalando hacia Renahue por angostos cajones cordilleranos.
El tramo que conecta Río Blanco con Reigolil presenta distintas condiciones geográficas que influyen en su desplazamiento. Al salir de Río Blanco, en la bifurcación de caminos, está la opción de desplazarse por el camino de vehículos, o bien subir hasta la terraza de Quililche

\section{RUTA CABURGA PILHUE}

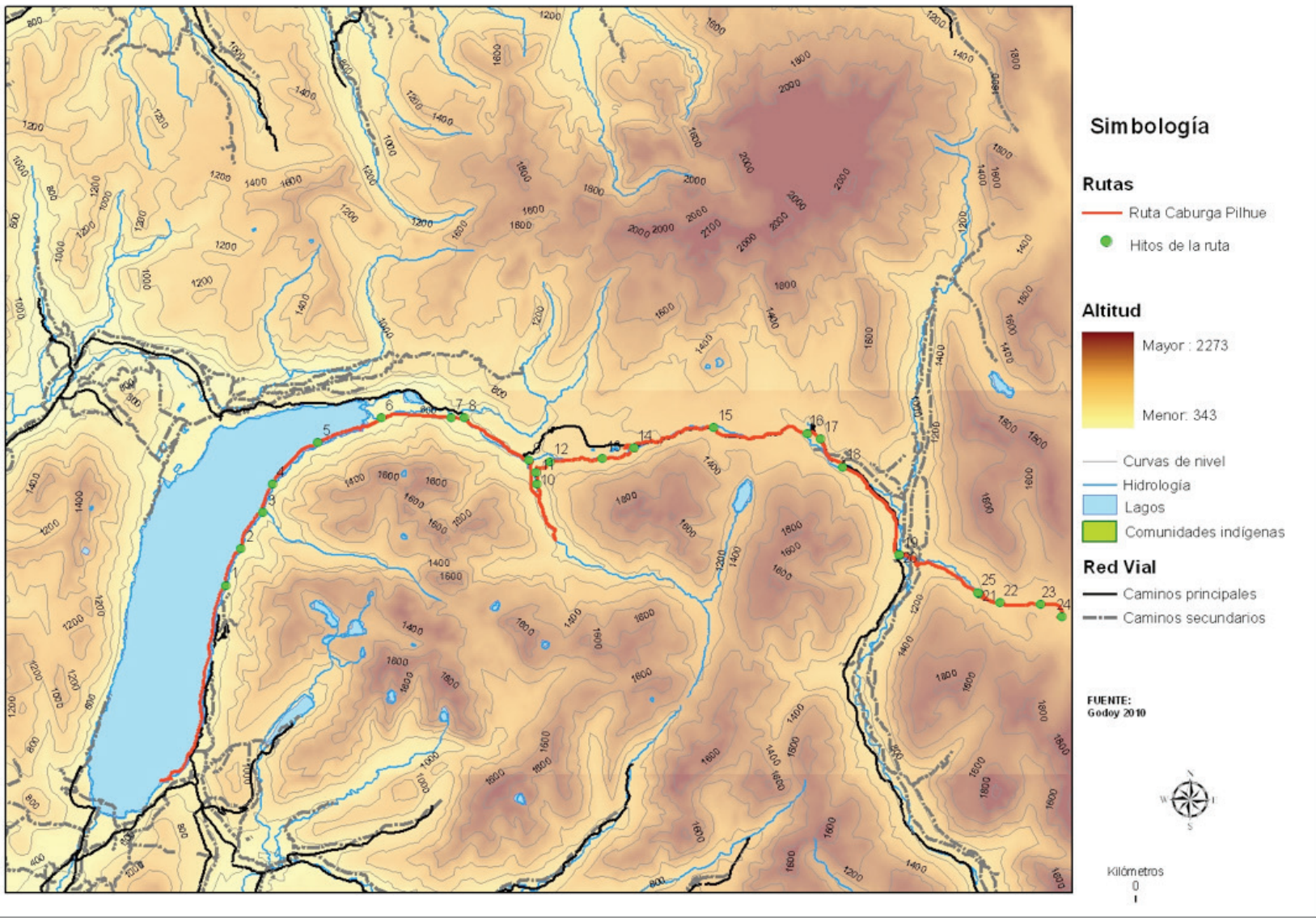


por una antigua huella ubicada al costado norte del camino, y con ello ahorrar la larga vuelta que hace el camino vehicular. Este camino escala la cota de 700-800 m.s.n.m. hacia una terraza donde comienzan a aparecer los primeros bosques de araucaria, por una huella angosta donde predominan los afloramientos rocosos, huellas cavadas en el limo por el tránsito de caballos y carretas (a modo de las rastrilladas consignadas por León), avanzamos por la terraza en dirección NE hacia los Nevados del Sollipulli.

Luego, en las terrazas de Quililche, se avanza hacia el oriente conectando con el nuevo camino para vehículos que abordamos a la altura de la casa de la familia Quirilao. Aunque el camino para vehículos se muestra en buenas condiciones, sus constantes pendientes alcanzan hasta los 1.128 m.s.n.m. Al llegar al sector de Portezuelos, se desprenden huellas que se dirigen al norte hacia la Laguna Cochor, y al sur hacia la Laguna Isolde. Desde allí comenzamos a bajar y subir -al menos tres pendientes- para finalmente acceder al Valle de Reigolil. El valle se presenta amplio y se despliega en una dirección norte sur, encajonado por los cuerpos montañosos y atravesado por el Río ReigolilMaichín, y dispuesto como un corredor norte sur, a los pies de los Nevados de Sollipulli.

En el valle se establecen comunidades indígenas en ambas orillas del río, algunas de las cuales están allí desde tiempos antiguos, mientras que otras comunidades están asentadas desde fines del siglo XIX, instaladas allí producto de la erradicación desde el proceso de "Pacificación de la Araucanía". Son esas comunidades las que preferentemente han utilizado los pasos hacia Argentina, dado que la conectividad por esos senderos hacía más efectivo el acceso a alimentos e insumos, que desplazarse a los poblados chilenos establecidos en cotas más bajas, principalmente por la ruta a Río Blanco Caburgua, y aún más complejo hacia el actual poblado de Curarrehue.

El último tramo de esta ruta corresponde al boquete de Reigolil - Pilhue, se accede atravesando el Río Reigolil, a través de una serie de pequeños puentes de vadeo hechos con troncos o tablones dispuestos entre las orillas por sobre el cuerpo de agua, y desde allí se aborda el portezuelo por un camino de ripio que avanza en dirección norte sur, en el cruce se toma el camino en dirección al este, hasta el Parque Nacional Villarrica-Hualalafquén, desde allí, por la ladera ubicada al sur de un estero, avanzamos hasta el hito del límite chileno-argentino. El hito está instalado sobre un peñón alto, cuya visibilidad permite contemplar la variación ecotonal del bosque de lenga-roble-raulí a un bosque predominante de ñirre. Del bosque espeso damos paso a un bosque mucho más bajo por una huella angosta sobre suelo limoso. Se observan huellas de caballos, humanos y motocicleta que dan cuenta de un uso frecuente del sendero. El tramo fue registrado hasta que salimos de la huella boscosa y llegamos a un valle en la cuenca del Lago Pilhue. La facilidad de acceder por este paso de escasas pendientes y altura lo hace transitable la mayor parte del año y, por ende, es y ha sido utilizado como camino para el abastecimiento permanente de las poblaciones locales.

La ruta Carbugua - Reigolil abarca un total de 40 kilómetros, presenta una variabilidad ecológica asociada a su variabilidad de altura, ya que en su punto más bajo, el Lago Caburgua, la altura promedio es de 500 m.s.n.m. Desde allí, el tránsito hacia las terrazas altas muestra un cambio abrupto entre las cotas en el tránsito entre Río Blanco y Quililche. Allí el desplazamiento es di- 


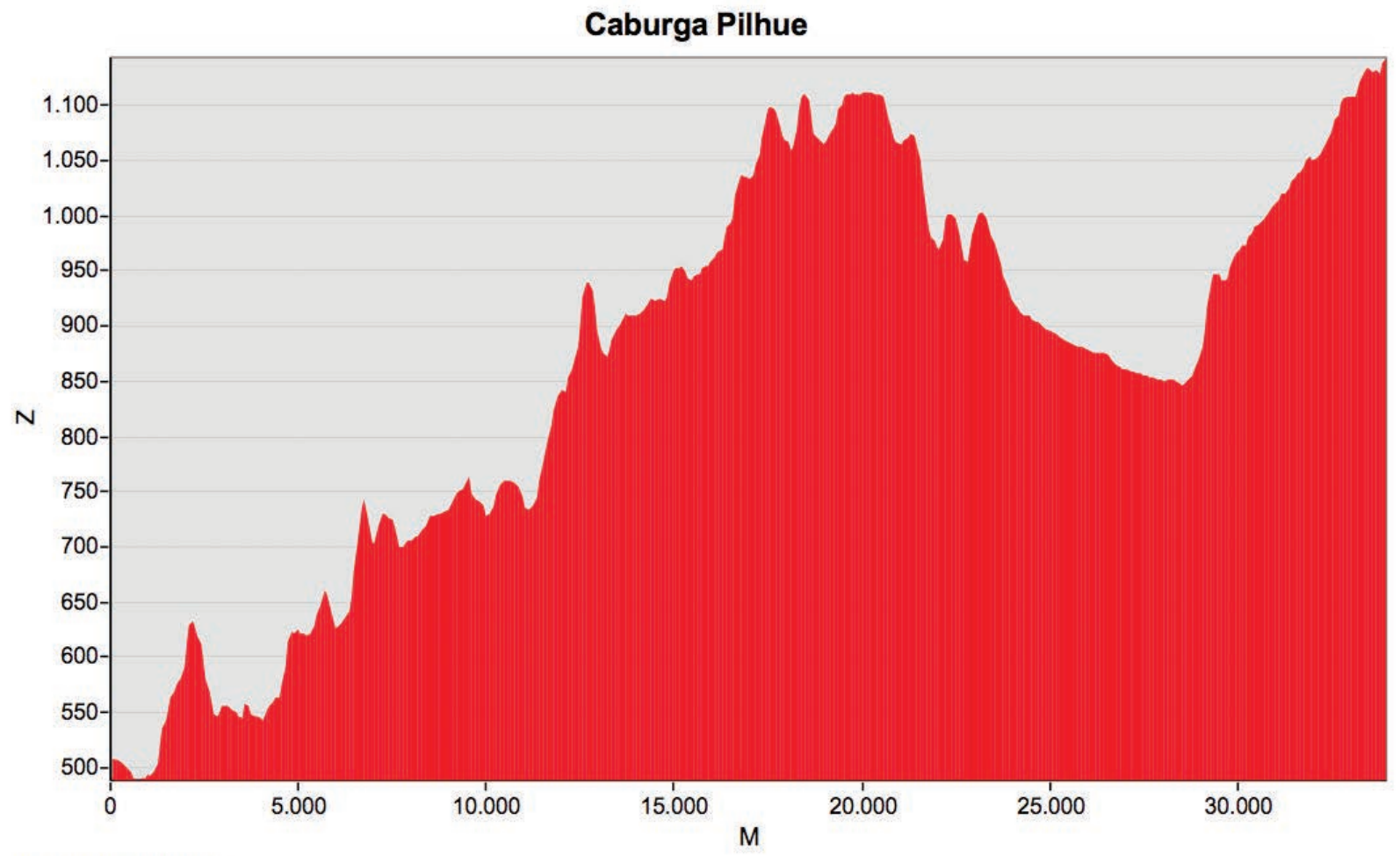

Profile Graph Subtitle

ficultado por la presencia de nuevas pendientes, que alcanzan alturas por sobre los 1.000 m.s.n.m., para posteriormente bajar hasta el Valle de Reigolil cuya altura alcanza los $800 \mathrm{~m}$. promedio, y de ahí se remonta el Portezuelo de Pilhue (entre los 900 a 1.000 m.). De acuerdo a los testimonios de don Juan Paredes ${ }^{12}$, esta ruta fue utilizada para movimiento de ganado entre Chile y Argentina, conectando los sectores de Renahue, Río Blanco, Quililche, Reigolil y

12 Don Juan Paredes y familia vive en el sector de Renahue en temporada de verano, durante abril realiza traslado de sus enseres y animales para su casa de invierno que se encuentra en el sector de Paillaco.
Pilhue (Argentina). La opción más antigua implica tomar la ruta de Río Blanco por Laguna Isolde hacia Reigolil. La estimación de movilidad por horas y a pie, planteada por Paredes, es la siguiente: desde Lago Caburgua a Renahue (Alero La Zueca) 2 horas, Renahue a Río Blanco 2 horas, Río Blanco a Laguna Isolde 5 horas, de Laguna Isolde a Reigolil 3 horas, y desde Reigolil a Pilhue 3 horas. En total, el tránsito de Chile a Argentina por esta huella es de aproximadamente 14 horas a pie. En nuestro caso, la experiencia de caminata requirió tres jornadas de 8 horas para poder conectar la zona de Caburgua (Chile) y Laguna Pilhue (Argentina). 


\subsubsection{Ruta Reigolil-Moquehue}

Esta ruta presenta un largo de 19 kilómetros, se encuentra en el Valle Alto de Reigolil, abarcando los sectores de Chocol, Reigolil, Los Traros y Pampa Chilena. El viaje se realiza caminando por el costado este del Río Reigolil, en camino de ripio y tierra con dirección sur norte, conectando el Valle de Reigolil con el sector de Alpe- hue, en los bajos de Melipeuco. El camino está asentado al costado este de los Nevados del Sollipulli, en una terraza fluvial que se encajona entre los nevados y la cordillera más baja. El camino se bifurca, uno en dirección a Llaima - Melipeuco, y el otro se dirige por huellas de pendientes suaves hasta una nueva bifurcación que separa el camino a la frontera, y el otro a la Laguna Huesquefilo.

\section{RUTA REIGOLIL MOQUEHUE}

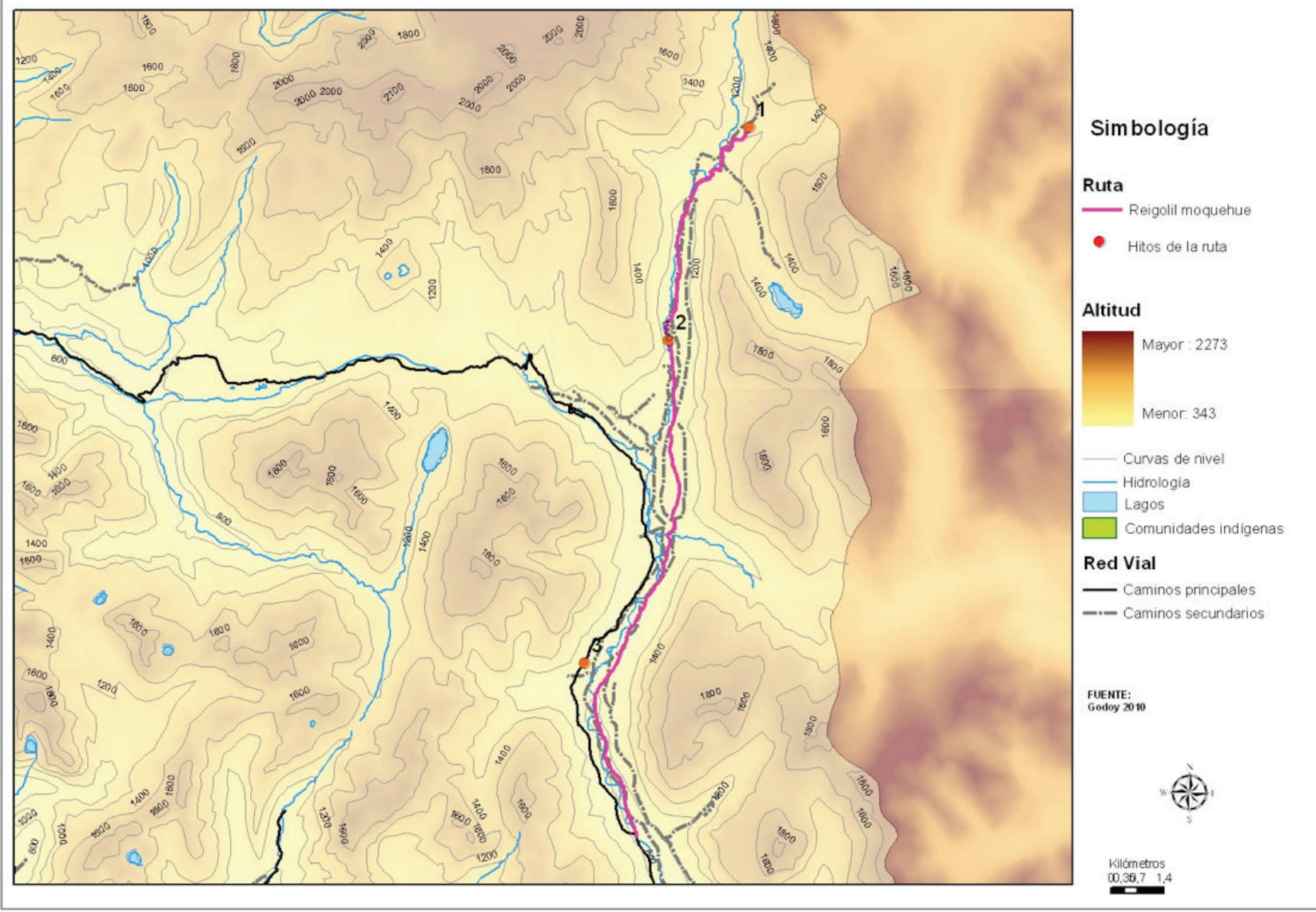


Una vez tomada la huella en dirección a la frontera con Argentina, se vadea un río y desde allí se avanza por una angosta terraza que precede a un conjunto de rastrilladas o huellas que bajan por las pronunciadas pendientes que anteceden la última terraza, donde el cambio hace evidente la aparición del tipo forestal de araucaria, en cotas ubicadas sobre los 1.000 m.s.n.m. De acuerdo a los testimonios recabados, esta ruta era utilizada para la explotación forestal hasta bien avanzado el siglo XX, y la producción de madera era destinada a Argentina. El uso forestal predominante de este paso, $y$ el hecho de que posee restricciones de ac- ceso estacional por su altura y la lejanía de los centros de abastecimiento, hace que su uso hoy sea esporádico y no constituya un paso de abastecimiento cotidiano y permanente en la actualidad.

De acuerdo al perfil de alturas que corresponde al Paso Moquehue o Nellocahue, se observa que el camino a orillas del Río Maichín se mantiene a una altura promedio de 850 m.s.n.m. para luego comenzar a elevarse hasta los 1.000 m.s.n.m. en un amplio espacio de recorrido por laderas en dirección al nororiente. En los tramos finales, la inclinación de las laderas se hace

Gráfico 2. Perfil de altitudinal de la ruta Reigolil-Moquehue

\section{Reigolil-Moquehue}

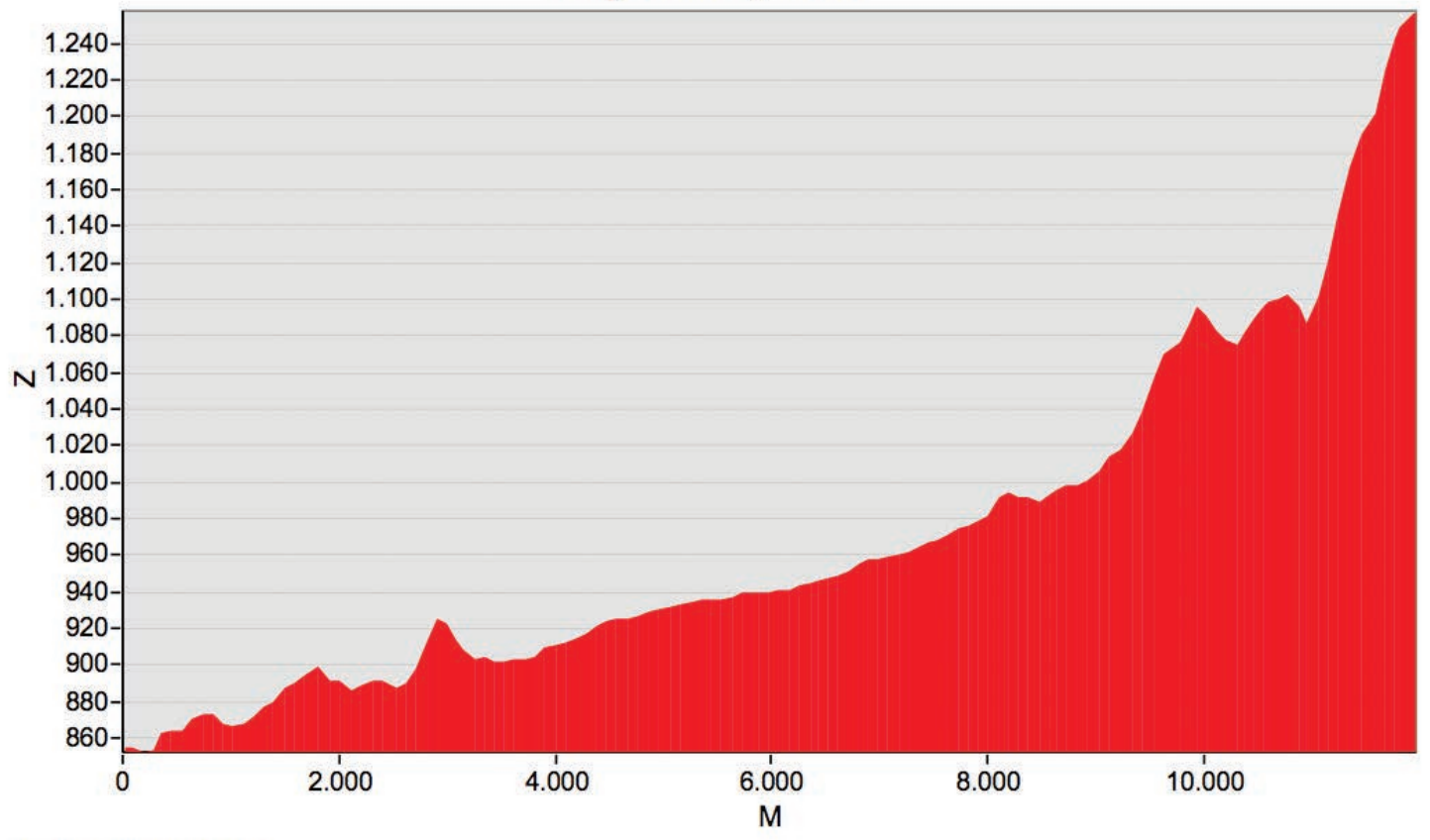

Profile Graph Subtitle 
más pronunciada, y desde allí se accede a una terraza más alta (Pampa Chilena). No se realizó bajada hacia el poblado de Aluminé (Argentina).

\subsubsection{Ruta Veta de Obsidiana de los Neva- dos del Sollipulli}

La ruta del Sollipulli para el acceso a las fuentes de materia prima para tecnología lítica, se encuentra al sur de la localidad de Melipeuco. Para llegar a la veta de piedra obsidiana, hoy se distinguen dos huellas, ambas ubicadas en la zona noroeste de los Nevados del Sollipulli, y se accede a ellas por el camino de ripio de 21 kilómetros que conecta el área urbana de Melipeuco con el sector noroeste de los Nevados del Sollipulli.

Para acceder se hace el recorrido que corresponde a un antiguo camino maderero de 4,5 kilómetros, que sube serpenteando la ladera noroeste del Sollipulli, y se avanza por él hasta llegar a una zona de antiguas terrazas de veranada, dada la abundante presencia de agua y pastizales. En la primera se observa una pe-

Imagen 6. Mapa de la ruta de acceso a la veta obsidiana Nevados de Sollipulli

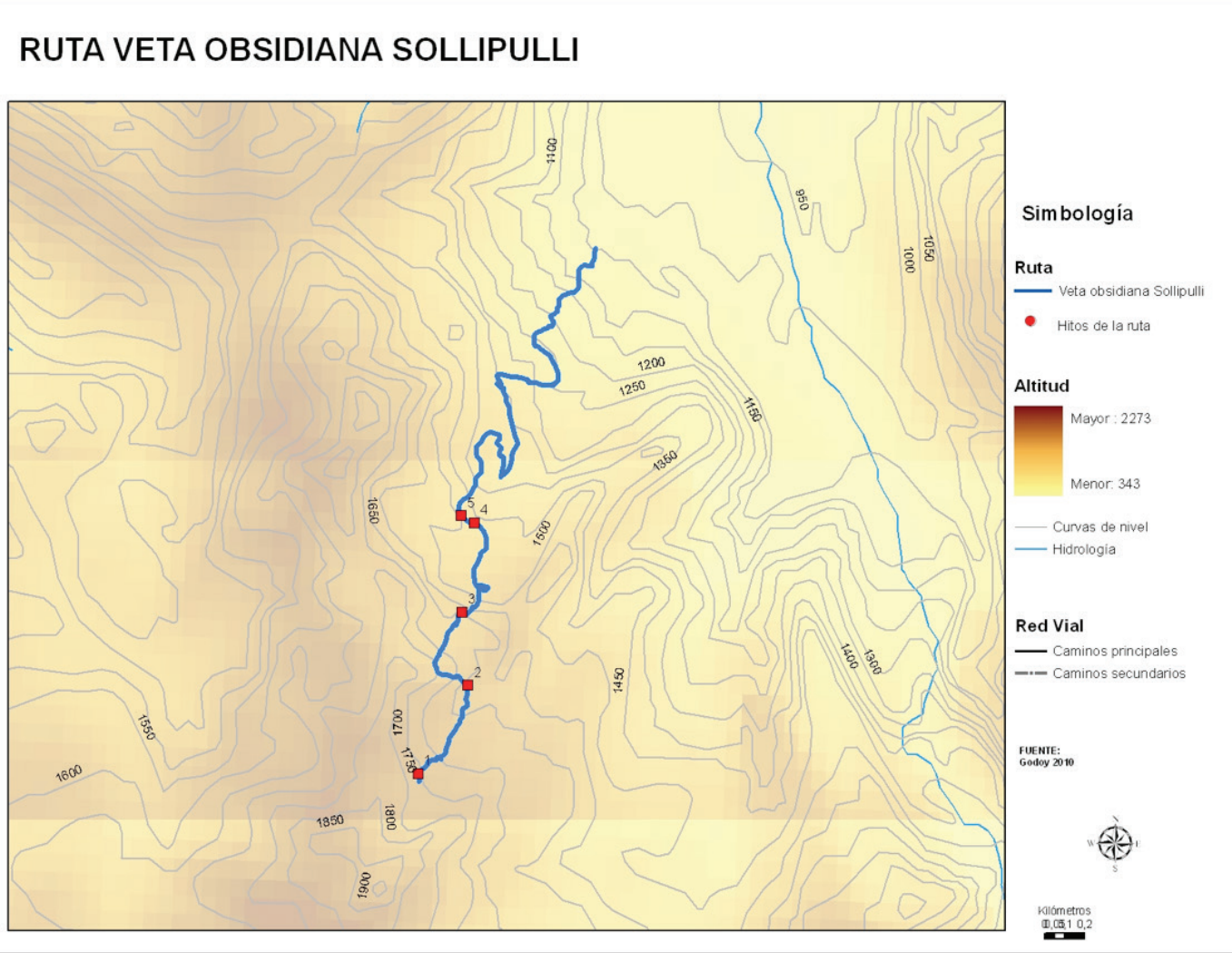


queña laguna y, muy cerca de allí, abundantes restos de lascas que corresponden a un sitio arqueológico. Más arriba nos encontramos con un valle de veranada bastante amplio, con abundante agua, y su ubicación en la ruta hace que sea la antesala a la fuente de obsidiana. Tras atravesar la terraza, se avanza en dirección este por una pendiente escarpada con abundante presencia de obsidiana de diversas calidades y colores. Al llegar a la cumbre, se distingue un mirador con cuantiosas piezas líticas, y desde allí se observa el río que se debe remontar para alcanzar la veta. Finalmente, la veta de obsidiana se dispone en relación a un curso de agua que baja por la ladera en dirección al noreste y tributa finalmente en el Río Alpehue. Los testimonios indican que la huella por la que transitamos corresponde a un camino forestal, y que durante la década de los 80 fue utilizado para el transporte de la obsidiana, materia que se explotó comercialmente.

Esta huella corresponde a la citada por Stern et al. (2009, 2008), y a la que se adscriben piezas líticas de los sitios del interior y de la costa de Chile. Desde el punto de vista de la tradición oral, en las comunidades mapuche del área no se reconoce la presencia de dicha fuente de

Gráfico 3. Perfil de altitudinal de la ruta de acceso a la veta obsidiana Nevados del Sollipulli

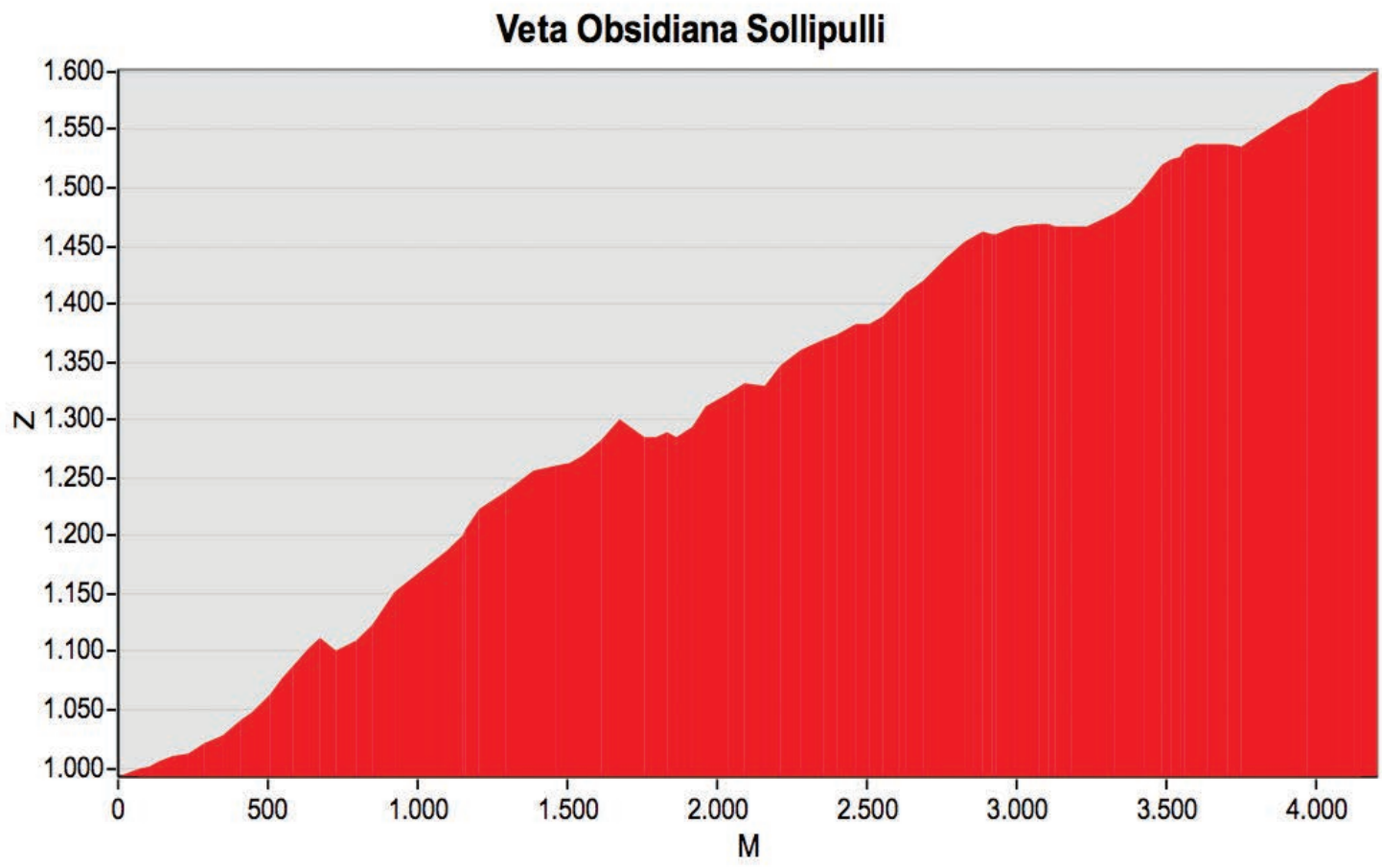

Profile Graph Subtitle 
materias primas, pero desde el punto de vista arqueológico, los trabajos realizados por Adán et al. (2010) y Navarro y Pino (1995) muestran una amplia red de sitios arqueológicos con presencia de este material lítico, distribuidos en un amplio radio que abarca desde el sitio Puente Quilo (en la comuna de Ancud, Chiloé), hasta el sitio Chan Chan (costa de Valdivia, Chile) y el sitio Cabeza de Indio (en la comuna de Melipeuco, Provincia de Cautín, región de la Araucanía).

El perfil describe el comportamiento de la ruta de acceso a la veta de obsidiana, el recorrido se realiza por una ladera de pendiente pronunciada, por una huella angosta que gran parte de las veces se ahonda por efecto del arrastre de madera y por acción de la lluvia. Al llegar a las zonas más altas se encuentran dos valles de veranada, uno de ellos pequeño pero con una pequeña laguna, más arriba se extiende una terraza alta, muy protegida del viento, con pastizales y abundante agua. El último tramo se extiende por una huella que conecta la terraza con el pequeño estero donde se concentra la fuente de obsidiana. Se accede a ella vadeando el río en diversos puntos, y posteriormente se ingresa al cajón en el que se encuentra la veta.

A partir del recorrido por estas vías, y a partir de los testimonios recogidos en las localidades, podemos señalar que los repu (senderos y sendas) de la cordillera son vías que se constituyen en la medida que se practica la movilidad, se conservan mediante su uso cotidiano, y se combinan con los caminos formalmente construidos, articulados, conservados y utilizados por obra de la burocracia desde tiempos coloniales.

Según los datos recogidos, podemos distinguir vías en uso y desuso, de exploración y esta- cionales. Las primeras son aquellas vías que poseen un tránsito diario y que, por lo tanto, permanecen limpias para su tránsito. Aquí cabe hacer la distinción entre los caminos locales (senderos, huellas y caminos de carretas) y los caminos que son parte de la infraestructura vial (caminos de ripio y asfaltados), ambos utilizados de manera combinada, según las condiciones de conectividad, las necesidades de transporte y la tecnología disponible en cada lugar.

Las vías en desuso son antiguas huellas y caminos que cierran su tránsito debido a su actual inactividad, o bien a usos muy eventuales. Sobre ellos permanecen testimonios sobre su utilización, y principalmente lo constituyen vías peatonales o de carretas que han dejado de ser utilizadas por la instalación de caminos para tránsito vial, o bien ante la pérdida de condición de bien público por la compra de privados de antiguas áreas de tránsito (como, por ejemplo, el caso del camino a la Laguna Huesquefilo, caído en desuso por cese de la actividad forestal y prohibición de uso forestal y/o forestal no maderero en los Parques Nacionales; otro caso se refiere a las vías que conectaban Caburgua con Río Blanco, en la costa este del lago homónimo, por la irrupción de las propiedades privadas de veraneo adquiridas por inmobiliarias o propietarios urbanos).

Por las vías de exploración de aquellas sendas se pretende acceder a zonas de poco o nulo acceso, y cuyo recorrido está asociado a satisfacer necesidades predominantemente económicas (por lo general acceso a zonas de recolección o de búsqueda de áreas de pastoreo). Aquí también predomina la problemática del acceso a predios que antiguamente eran de propiedad indígena y que hoy están en manos de privados. 
Por su parte, los senderos y sendas estacionales se refieren a aquellas rutas cuyo uso está regido por razones climáticas o geográficas que impiden su tránsito en todo el ciclo anual, así como aquellos caminos que son utilizados para la extracción de determinados recursos en las diferentes estaciones del año, como ocurre, por ejemplo, con los caminos asociados al acceso de zonas de invernada y veranada para ganado, corte y venta de colihue, recolección de piñones, y para actividades sociales como la de mantener contacto con familiares, o asistir a la celebración de nguillatunes, entre otras (Godoy 2009).

\section{Conclusiones}

El área que comprende los Nevados del Sollipulli hasta Villarrica debe entenderse como un espacio límite-frontera, en primer lugar, por su cercanía a un límite político administrativo esbozado en la colonia española mediante la construcción de fortines indígenas y españoles (Mera et al. 2004), pero definido en términos político-administrativos como tal a partir del surgimiento del estado republicano (Pinto 1996). En segundo lugar, es un espacio fronterizo en el sentido que supone la existencia de una diversidad ecosistémica definida por la presencia de varias formaciones boscosas que permiten la presencia estacional de variados recursos, y a la cual accedieron grupos diversos, lo que eventualmente podría implicar relaciones sociales que oscilaron entre el conflicto y las alianzas.

Es interesante observar que este territorio complejo en su acceso -dadas las restricciones estacionales y de accidentes geográficos- constituye una región con una tradición oral significativa, que da cuenta de un conjun- to de conocimientos y prácticas mapuche que se mantiene, y que en términos de movilidad, da cuenta de la permanencia de sistemas de tránsito que se alternan con espacios que son usados estacionalmente, y otros que definitivamente han desaparecido de la práctica (por variadas razones, desde eventos geológicos hasta situaciones de orden económico-administrativo), pero sobre los que se mantiene una frágil y significativa memoria.

Las prácticas de movilidad dan cuenta de un conocimiento de la geografía y del comportamiento del clima, frente al cual se establecen usos del territorio en virtud de la estacionalidad, ya sea por la disponibilidad de recursos o por cuestiones de acceso por razones climáticas. Por lo tanto, se observa la generación de un conocimiento fundamental para interpretar y definir las actuaciones de movilidad. Parte de este este conocimiento facilita el desarrollo de tecnologías específicas a los recursos, en este contexto, es interesante el uso de canoas monóxilas como un medio de transporte utilizado hasta mediados del siglo, cuando fueron reemplazadas por embarcaciones de madera más livianas, y a la irrupción de vapores, que facilitaron el traslado de carga y pasajeros. Además, las aplicaciones tecnológicas de la madera dan cuenta de su uso para variados instrumentos que facilitaron el transporte y la comunicación. Del mismo modo, llama la atención la existencia de modalidades de comunicación institucionalizadas mediante el uso del humo y aplicaciones del sonido.

Finalmente, es importante recalcar los valores de la cosmovisión mapuche en la construcción del imaginario del territorio, en el sentido de que se define un eje del mundo cuyas antípodas se plantean en un eje oeste-este, a diferencia de 
la actual visión occidental de norte-sur. Junto a este ordenamiento, los testimonios evidencian un profundo conocimiento del territorio, que facilita resolver cuestiones de orden pragmático en la movilidad, y también permite evidenciar el poder de los antiguos loncos y ngempines para trazar caminos, donde resultaba imposible el tránsito de un lugar a otro.

La experiencia de haber recorrido los caminos y huellas aquí descritos, no sólo permitió generar una sencilla cartografía de los recorridos, sino que permitió conocer una memoria que da cuenta de la existencia de un sistema de prácticas y de construcción de realidad que aún sobrevive -aunque sea en el recuerdo de unos pocos- de lo que significa vivir en la Araucanía
Andina, y donde la cordillera no representa un obstáculo para la vida, sino más bien un continuo territorial del mundo mapuche, que se extiende desde el Océano Pacífico hasta el Océano Atlántico, o mejor dicho, desde los bosques frondosos de la selva valdiviana hasta los solitarios paisajes de la estepa patagónica.

Dedicado a la memoria de: Don Pedro Punoy, Don José Marifilo, Doña Rosa Antihuala, Don Guillermo Reucán.

Agradecimientos a:

Don Fermín Quintunahuel, Don Santiago Carinao, Don Alberto Colipe, Don Fernando Huaquifil y familia, Doña Elvira Valenzuela, Doña Tante Hilde, Don José Paredes, al profesor Roberto León, y a todos los que han colaborado en el desarrollo de esta investigación.

\section{Bibliografía}

Adán, L. et al. 2010. "La tradición arqueológica de bosques templados y su estudio en la región lacustre cordillerana de las regiones IX y XIV (Centro-Sur de Chile)". Actas del XVII Congreso Nacional de Arqueología Chilena. Valdivia, Chile.

Albornoz, A. y Hajduk, A. 2001. "Antecedentes arqueológicos e históricos del "Camino de las Lagunas"”. Tiempos Patagónicos 7: 24-29. Buenos Aires: Facultad de Derecho y Ciencias Políticas, Universidad Católica Argentina.

Alvarado. M y Mera. R. 2004. "Estética del paisaje y reconstrucción arqueológica. El caso de la región del Calafquén (IX y X región-Chile)". Revista Chungará 46 (2): 559-568.

Ancán, J. 2002. Voces Mapuche. Santiago: Museo Chileno de Arte Precolombino.

Bellelli, C., Scheinshon, V. y Mercedes, M. 2008. "Arqueología de pasos cordilleranos: Un caso de estudio en Patagonia Norte durante el Holoceno Tardío". Boletín del Museo Chileno de Arte Precolombino 13 (2): 37-55.

Berenguer, J. et al. 2005. "El Qhapaqñan en el Alto Loa, norte de Chile: Un estudio micro y macromorfológico". Revista Estudios Atacameños 29: 7-39.

Careri, F. 2002. Walkspaces. Barcelona: Editorial Gili.

Castro, V. 2004. "Riqueza y complejidad del Qhapaq Ñan. Su identificación y puesta en valor". Tejiendo los lazos de un legado. Qhapaq Ñan - Camino Principal Andino: Hacia la nominación de un patrimonio común, rico y diverso, de valor universal. Caraballo, C., Sanz, N. y Finocchietti, S. (Coords.). Lima: UNESCO. 40-47.
Criado, F. 1991. "Construcción social del espacio y reconstrucción arqueológica del paisaje". Boletín de Antropología Americana 24: 5-30.

Foerster R. y Gundermann, H. 1996. "Religiosidad Mapuche Contemporánea: Elementos Introductorios". Culturas de Chile. Etnografía Sociedades Indígenas Contemporáneas y su Ideología. Hidalgo J. et al. (Eds.). Santiago: Editorial Andrés Bello. 189-240.

Godoy, M. 2009. "Estacionalidad y manejo de recursos naturales del bosque templado: Una aproximación etnográfica y etnoarqueológica en la cuenca fluvial Valdivia". Revista Austral de Ciencias Sociales 15: 73-95. y Lira, N. 2007. "Etnoarqueología para la comprensión de las canoas del Lago Calafquén, Panguipulli, Región De Los Ríos, Chile”. Actas del XV Congreso Chileno de Antropología. Valdivia, Chile.

Grebe, M. E., Pacheco, S. y Segura, J. (1972). "Cosmovisión mapuche". Cuadernos de la Realidad Nacional 14: 46-73.

León, L. 1991. Maloqueros y conchavadores. Temuco: Ediciones Universidad de La Frontera.

Mera, R. et al. 2004. "Sitios históricos tempranos de carácter defensivo. Sector Oriental de la Villa Rica (1550-1602)". Revista Chungará 36 (suppl.): 175-186.

Navarro, X. y Pino, M. 1995. "Interpretación de ocupaciones precerámicas y cerámicas en los distintos micro ambientes de la costa de Chan Chan, Valdivia, X Región". Actas del XIII Con- 
greso Nacional de Arqueología Chilena 1:127-134.

Pimentel, G. 2004. Vías de circulación del período intermedio tardío (900-1450 D.C). Tesis para optar al título profesional de arqueólogo. Departamento de Antropología: Universidad de Chile.

Pinto, J. (Ed.). 1996. Araucanía y pampas. Un mundo fronterizo en América del Sur. Temuco: Ediciones Universidad de La Frontera.
Stern, Ch. et al. 2009. "Fuentes y distribución de diferentes tipos de obsidianas en sitios arqueológicos del Centro-Sur de Chile (38-44S)". Revista Magallania 37 (1): 179-192.

2008. "Nueva fuente de obsidiana en la Región

de la Araucanía, centro-sur de Chile: Química y contexto arqueológico de la obsidiana riolítica negra de los Nevados de Sollipulli". Revista Magallania 36 (2): 185-193. 
